\title{
An Operation Optimization for Express Freight Trains Based on Shipper Demands
}

\author{
Yuzhao Zhang ${ }^{1,2}$ and Yusong Yan ${ }^{2}$ \\ ${ }^{1}$ School of Traffic and Transportation, Lanzhou Jiaotong University, Lanzhou 730070, China \\ ${ }^{2}$ School of Transportation \& Logistics, Southwest Jiaotong University, Chengdu 610031, China \\ Correspondence should be addressed to Yuzhao Zhang; yuzhaozhang@126.com
}

Received 18 November 2013; Revised 16 December 2013; Accepted 24 December 2013; Published 12 January 2014

Academic Editor: Wuhong Wang

Copyright (c) 2014 Y. Zhang and Y. Yan. This is an open access article distributed under the Creative Commons Attribution License, which permits unrestricted use, distribution, and reproduction in any medium, provided the original work is properly cited.

\begin{abstract}
The supreme goal of railway express freight transportation is to meet the various demands of shippers. This paper considers the optimization problem of the operation plan for express freight trains based on shipper demands, including transport volume, service frequency, and transit time. An integer programming model that takes maximum shipper demands as optimized objective is proposed to realize the assignment of trains to candidate paths. In this model, the number of marshalling cars for express freight train is set as a decision variable rather than a constant to better satisfy the demand characteristics. A heuristic solution algorithm based on genetic algorithm is then designed. Finally, a numerical case is applied to verify the feasibility of the model and the algorithm.
\end{abstract}

\section{Introduction}

Express freight has an important role in the whole freight transportation system. With the constant increase in energy cost, the increasing seriousness of traffic congestion, and environmental pollution, the express freight transportation system that takes aviation and expressway as the main modes reflects many problems [1]. Many countries have paid more attention to the development of rail express freight transportation, which is more energy-saving and environment friendly [2]. Being the foundation of the railway freight transportation organization, operation plan of express freight trains is to determine the set of trains to satisfy the express freight demands. Compared with bulk freight, express freight has the characteristics of small batch, excellent timeliness, and high value, and the shippers have higher requirements on service quality, but lower sensitivity on the transport cost. Consequently, the characteristics and shipper diversified demands of express freight should be considered when determining and optimizing the train operation plan.

In the past decades, various attempts have been made to gain optimal transportation scheme for railway express freight demands. These attempts mainly involve three kinds: design of formation plan for direct freight trains, service network design of express freight, and determination of operation plan for express freight trains.

Formation plan of direct freight trains determines the transport scheme of car flows by direct trains, including direct trains in the loading place and the technical station [3]. Many express freight trains are direct trains, and freight demands can be converted into car flows; thus, its determination method can provide references for the optimization of operation plan for express trains. Lin et al. [3] have researched on train formation plan problem for a long time and achieved mature modeling approaches that take minimum time consumption of car flows as objective and 01 programming model as basis. Crainic et al. [4] established a mixed integer planning model for railway freight transportation to realize the strategy plan of enterprise resources, which aims to minimize the operating cost of transportation enterprise. Marín and Salmerón [5] formulated a model of assigning the trains and the demand of cars to routes for rail freight networks and designed different heuristic algorithms involved in simulated annealing, Tabu search, and descending to respond to large scale network. Yaghini et al. [6] proposed a population-based genetic algorithm for railway 
blocking problem and then compared the solution quality and the computational time of the algorithm with the optimization solver software, which showed that the proposed algorithm has high efficiency and effectiveness. Martinelli and Teng [7] built a nonlinear integer programming model for railway operation plan taking the minimum operation time as objective and presented neural network to solve the model.

Designing reasonable service network to meet express freight demands is another important aspect. Crainic [8] classified the service network design of freight transportation enterprise into service frequency design and dynamical service network design and established two kinds of frequency design models with dynamic service network design model based on space-time network. Lin and Chen [9] contrived hub-and-spoke service network with the limitation of transit time for express delivery enterprises. Although this method has no direct influence on railway express transportation, the idea can provide experience for the service network design of railway express freight. Ceselli et al. [10] established three models for the express service network of Swiss federal railways applying different methods and designed corresponding solution methods that include commercial solver approach, branch-and-cut approach, and column generationbased approach.

In recent years, the number of studies on express freight train operation plan has been increasing. Ben-Tal et al. [11] proposed an operating-plan model (OPM) for the Santa Fe Railway and designed a combination algorithm using genetic and tabu searches; the application of the OPM reduced 4 percent to 6 percent of the operation costs for the company. Wang and Liu [12] discussed the operation optimization problem of special parcel trains without fixed demands and capacity constraint and determined the running sections, number, and marshalling of trains by establishing a linear programming model. Yano and Newman [13] took the minimization sum of transportation cost and holding cost as objective and formulated an optimization model and an algorithm for the scheduling problem of trains and containers with due dates. Crevier et al. [14] constructed a bilevel model for the operation plan of rail freight transportation comprehensively considering the pricing policy and network capacity and then designed an exact solution approach based on branch-andbound algorithm. Guo et al. [15] put forward a linear integer programming model for the operation plan of scheduled transit trains and solved the problem using Lingo software.

These studies have provided useful references for the design and optimization of express freight trains operation plan. Nonetheless, most of the present researches formulate models based on the operation with less consideration on the shipper demands. The number of marshalling cars for express freight trains is usually set as a constant. According to the characteristics of express freight, the operation plans of express freight trains with flexible marshalling are more suitable. Furthermore, the problem of operation plan for express freight trains is often solved by the exact solution methods, which cannot work when the network scale is large. This paper focuses on shipper demands of express freight and proposes a model considering flexible marshalling of express

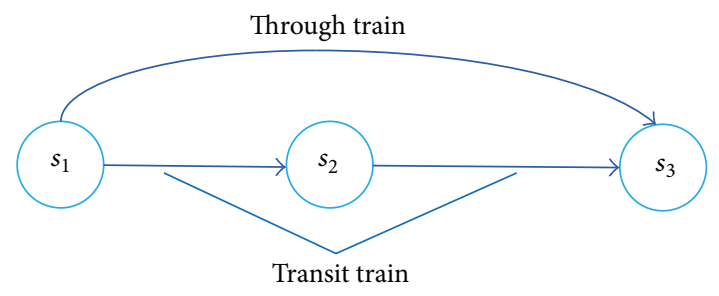

FIGURE 1: Illustration of express freight train kinds.

freight trains, and a heuristic algorithm will be designed to solve the model.

The remainder of the paper is organized as follows. An optimization model for operation plan of express freight trains based on shipper demands is established in Section 2, and then the solution algorithm on the basis of genetic algorithm is designed in Section 3. In Section 4, a numerical example is provided to verify the effectiveness of the model and the algorithm. The last section gives some conclusions and the possible areas of further research.

\section{Model Formulation}

2.1. Problem Statement. Express freight trains can be sorted into two classifications, namely, through trains and transit trains, depending on their operation. For example, Figure 1 shows a simple railway network composed of three organization stations of express freight and two sections. The trains with origin and destination stations ( $s_{1}$ and $s_{3}$ ), which only consist of car flows from $s_{1}$ to $s_{3}$ and without reorganization in station $s_{2}$, belong to the first classification, whereas the others belong to the second classification. By organizing transit trains, the converging time of car flows can be reduced, but the transit time and transit cost will increase. This paper only considers the operation problem associated with the first classification express freight trains. In the light of shipper demands with consideration to the benefit of railway transportation enterprise, the origin and destination stations, running paths, number of marshalling cars, and running frequency of express freight trains will be determined under the network condition. In this paper, the number of marshalling cars was set as a decision variable, so the operation plan with flexible marshalling was formulated.

Aside from the basic requirement on security, shippers of express freight have higher expectation on transportation services, including satisfaction degree of demand, transport time, and transport convenience but have lower sensitivity to transport cost [15]. This paper mainly considers these expectations of shippers when establishing the model, which takes maximum transport volume as the objective and meeting the requirement of transport time and convenience as constraints. In Particular the transport convenience constraint is realized by making the running frequency of express freight trains more than the desired service frequency of shippers. In addition, constraints in the number of marshalling cars and station capacity, as well as section capacity are also considered. 
The operation plan of express freight trains is a complex integrated optimization problem, and the following assumptions are made to reduce the difficulty in establishing the model.

(1) The stations being considered in this paper are only the organizing stations and handling stations of express freight, which have favorable distribution conditions, and can meet the requirement of departure and arrival for the whole train.

(2) The classification and transportation conditions of goods are not considered, while supposing the grades of all the express freight trains are the same.

(3) The loading capacity of each car is identical, indicating the freight volume loaded on every car is the same. Furthermore, freight demands are converted into car flows of each day, and the traction tonnages of each section are also denoted by the traction cars.

(4) The candidate paths of each express freight demand are determined, and the running path of the same demand is consistent.

2.2. Definitions and Notations. We define the following notations to describe the proposed model:

$G(S, E)$ : railway physical network;

$S$ : set of station in $G$, and we denote a station by $s$;

$E$ : set of edge in $G$, and we denote an edge by $e$;

$Q$ : set of express freight demand $O D$, and we denote a demand $O D$ by $q$;

$\mathrm{O}_{q}$ : origin station set of $q$;

$D_{q}$ : destination station set of $q$;

$n^{q}$ : freight volume of $q$, and we transfer it into number of cars;

$f^{q}$ : desired service frequency of $q$;

$t^{q}$ : desired transit time of $q$, including the overall time from origin to destination;

$P_{q}$ : set of path for $q$; we denote a path by $p$, which can be expressed by a serial set of stations, and the first element is the original station of the path, while the final element is the destination station;

$P$ : set of all paths, and $P=\cup_{q \in Q} P_{q}$;

$t_{p}:$ transit time by path $p$;

$f_{p}$ : service frequency on path $p$, and it is expressed by the number of trains operating on path $p$ every day, while its value is within a range of nonnegative integers;

$n(s)$ : departure and arrival capacity of station $s, \forall s \in S$;

$n(e)$ : carrying capacity of edge $e, \forall e \in E$.

We define two decision variables as follows. $x_{p}^{q}$ : binary variable that denotes the choice of path for demand $q ; x_{p}^{q}$ equals to 1 if freight $q$ was distributed to path $p$, indicating express freight trains are operated on path $p$, while 0 otherwise.

$y_{p}$ : number of marshalling cars on path $p, \forall p \in P$, if $x_{p}^{q}=0$; then $y_{p}=0$, otherwise if $x_{p}^{q}=1$, then $y_{p} \in N$.

2.3. Objective Function. This paper takes maximum transport volume as the objective function, so that the operation plan can transport freights as much as possible to satisfy shipper demands. The objective function can be expressed as follows

$$
\operatorname{Max} Z=\sum_{q \in \mathrm{Q}} \sum_{p \in P_{q}} x_{p}^{q} y_{p} f_{p} .
$$

\subsection{Constraint Conditions}

2.4.1. Service Frequency Constraint. The service frequency of express freight trains should not be less than the minimum desired frequency of shippers. The service frequency of demand $q$ on path $p$ can be expressed by $\sum_{p \in P_{q}} x_{p}^{q} f_{p}$; thus, for $\forall q \in Q$, the constraint is expressed by the following inequality:

$$
\sum_{p \in P_{q}} x_{p}^{q} f_{p} \geq f^{q}
$$

Only if path $p$ was selected to transport freight, there will be trains operating on this path, and the service frequency $f_{p}$ belongs to a range of positive integers which are bigger than $f^{q}$. Otherwise, $f_{p}$ equals 0 . Consequently, the following formula is obtained:

$$
f_{p}= \begin{cases}0, & \text { if } x_{p}^{q}=0 \\ f_{p} \geq f^{q}, f_{p} \in N, & \text { if } x_{p}^{q}=1 .\end{cases}
$$

2.4.2. Transit Time Constraint. Due to the high timeliness of express freight, the transit time should be within the requirement time range in the process of express freight transportation. The expression is as follows:

$$
\sum_{p \in P_{q}} x_{p}^{q} t_{p} \leq t^{q}
$$

2.4.3. Number of Marshalling Cars. The number of marshalling cars for express trains will be equal to 0 if $x_{p}^{q}=$ 0 . Otherwise, if $x_{p}^{q}=1$, the number will be within a range of positive integers, of which the upper limit value is the minimal traction cars of each section on the path and the lower limit value should ensure the benefit of railway enterprise. As a result, the number of marshalling cars for express freight trains can be expressed by the following formula:

$$
y_{p}= \begin{cases}0, & \text { if } x_{p}^{q}=0 \\ m_{p}^{\min } \leq y_{p} \leq m_{p}^{\max }, y_{p} \in Z^{+}, & \text {if } x_{p}^{q}=1\end{cases}
$$




Upper layer \begin{tabular}{|l|l|l|l|l|l|l|l|l|l|l|l|}
\hline 1 & 0 & 0 & 1 & 1 & 0 & 1 & 0 & 0 & 1 & 0 & 1 \\
Choice of path \\
Lower layer
\end{tabular} \begin{tabular}{|l|l|l|l|l|l|l|l|l|l|l|l|}
20 & 0 & 0 & 25 & 22 & 0 & 30 & 0 & 0 & 24 & 0 & 20 \\
Number of marshalling cars
\end{tabular}

FIGURE 2: Illustration of chromosome coding approach.

where $m_{p}^{\min }$ and $m_{p}^{\max }$, respectively, denote the minimum number and the maximum number of marshalling cars for express freight trains on path $p, \forall p \in P$.

2.4.4. The Relationship between Transport Volume and Demand. For $\forall q \in Q$, the overall volume transported by all paths should not exceed the amount of transportation demand, which can be expressed as follows:

$$
\sum_{p \in P_{q}} x_{p}^{q} y_{p} f_{p} \leq n^{q}
$$

2.4.5. Car Flow Constraint. According to the fourth assumption, one group car flow can only be allocated to one path then, for $\forall q \in Q$, we can get the following inequality:

$$
\sum_{p \in P} x_{p}^{q} \leq 1
$$

When $\sum_{p \in P} x_{p}^{q}=1$, the car flow of $q$ is distributed to a path $p$, indicating $q$ is transported by trains operating on path $p$. If $\sum_{p \in P} x_{p}^{q}<1$, then $q$ is not distributed to any path, indicating it is not transported.

2.4.6. Carrying Capacity Constraint of Each Section. The number of running trains on each section should not exceed its carrying capacity. Set $\delta_{p}^{e}$ as an auxiliary binary variable; $\delta_{p}^{e}$ takes value 1 if $e \in p$ and 0 otherwise; then, the constraint of carrying capacity can be expressed as follows:

$$
\sum_{p \in P} x_{p}^{q} \delta_{p}^{e} f_{p} \leq n(e) .
$$

2.4.7. Departure and Arrival Capacity Constraint. The total number of trains departing from station $s$ and arriving at it could not exceed its departure and arrival capacity, which can be expressed by the following formula:

$$
\sum_{q \in \mathrm{Q}} \sum_{p \in P_{q}} x_{p}^{q} \varphi_{p}^{s} f_{p} \leq n(s)
$$

where for $\forall s \in O_{q} \cup D_{q}$, incidence vector $\varphi_{p}^{s}$ takes value 1 if $s \in p$ and 0 otherwise.

\section{Algorithm Design}

The proposed model is a nonlinear integer programming model, which belongs to NP problem. It is difficult to solve by traditional exact solving methods and commercial solver, especially when the network scale is large, getting the solution is nearly impossible [16]. Thus, we design a heuristic genetic algorithm for the problem to get a satisfying solution within a tolerable time range.

3.1. Coding Approach. Aiming at the two-group decision variables of the model, a bilayer coding structure $[17,18]$ is adopted in this paper. A binary number embedded with the upper layer coding denotes the choices of paths, where the value 1 indicates the path being selected and 0 otherwise. A nonnegative integer embedded with the lower layer coding indicates the number of marshalling cars for express freight train; if a path is chosen, then the integer is within $\left[m_{p}^{\mathrm{min}}\right.$, $\left.m_{p}^{\max }\right]$; otherwise, the integer is zero. The length of chromosome equals the total number of candidate paths $M$.

Figure 2 illustrates a bi-layer coding chromosome, the length of which is 12 . The number range of marshalling cars is $[20,30]$, and six paths are chosen to operate express freight trains, whose numbers of marshalling cars are, respectively, $20,25,22,30,24$, and 20 .

3.2. Initialization of Group. Get the value of the upper layer gene by generating a binary array randomly with the length of $M$ and then corresponding gene value of the lower layer is formatted in view of the binary array. Supposing the population size is $N$, the initial population can be obtained by the above mentioned way. All chromosomes have to be tested according to the constraints. If an individual is infeasible, necessary adjustment will be carried out. Particularly, the total number of chosen paths for any demand $q$ should not exceed 1 ; in order to enhance the solving efficiency, we let the initial number equal 1 . The $x_{p}^{q}$ taking value 1 associated with demand $q$ should be reduced by 1 with descending order if the total number of chosen paths exceeds 1 , until the condition is satisfied. Contrarily, if the total number of chosen paths for demand $q$ equals 0 , then choose a candidate path randomly associated with $q$. The number of marshalling cars for each path should be adjusted with the change of $x_{p}^{q}$. As showed in Figure 3, the values enclosed in each couple curly braces represent the choice of each demand, and a new chromosome can be obtained after the adjustment of the original one if the values of $m_{p}^{\min }$ and $m_{p}^{\max }$ are 20 and 30 , respectively. Moreover, chromosomes should also be tested and adjusted to ensure their feasibility after any genetic operation.

3.3. Fitness Function. For the proposed model, the objective function is a maximum problem, while the function value of which is nonnegative, so the objective function of the proposed model is taken as the fitness function. 


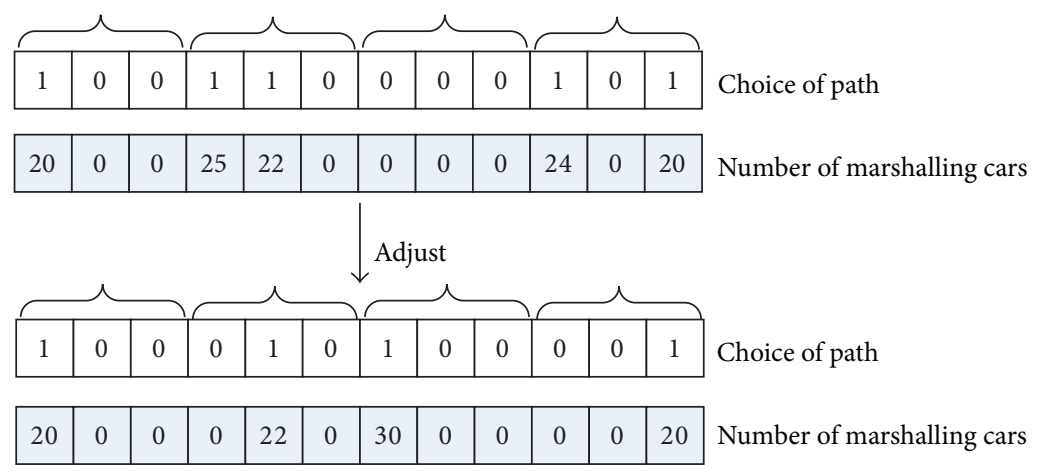

Figure 3: Adjustment of unfeasible chromosome.

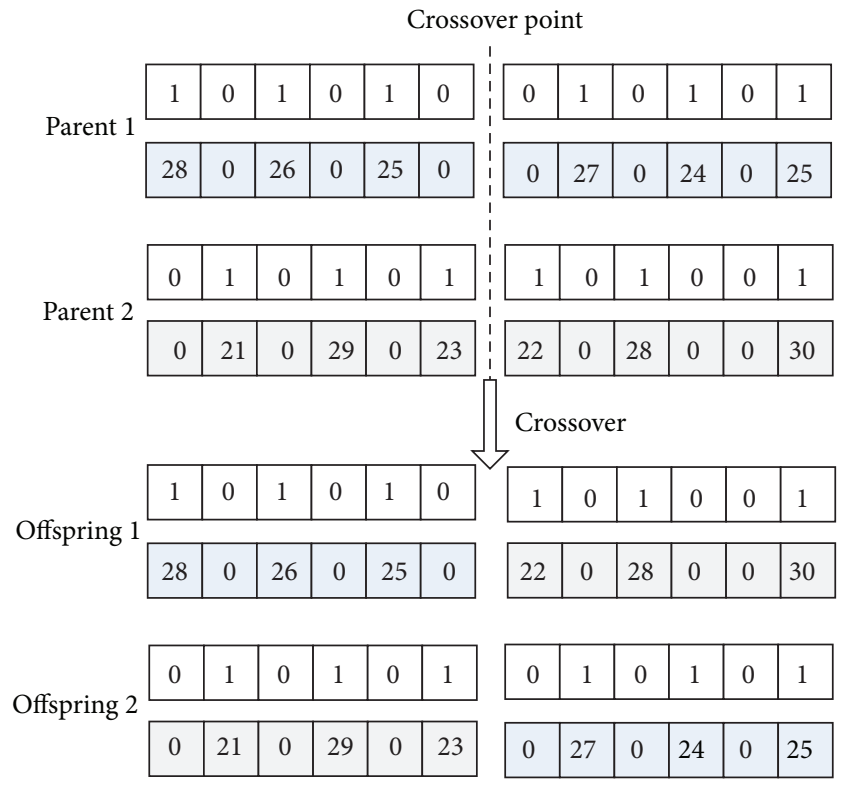

(a) Single-point crossover

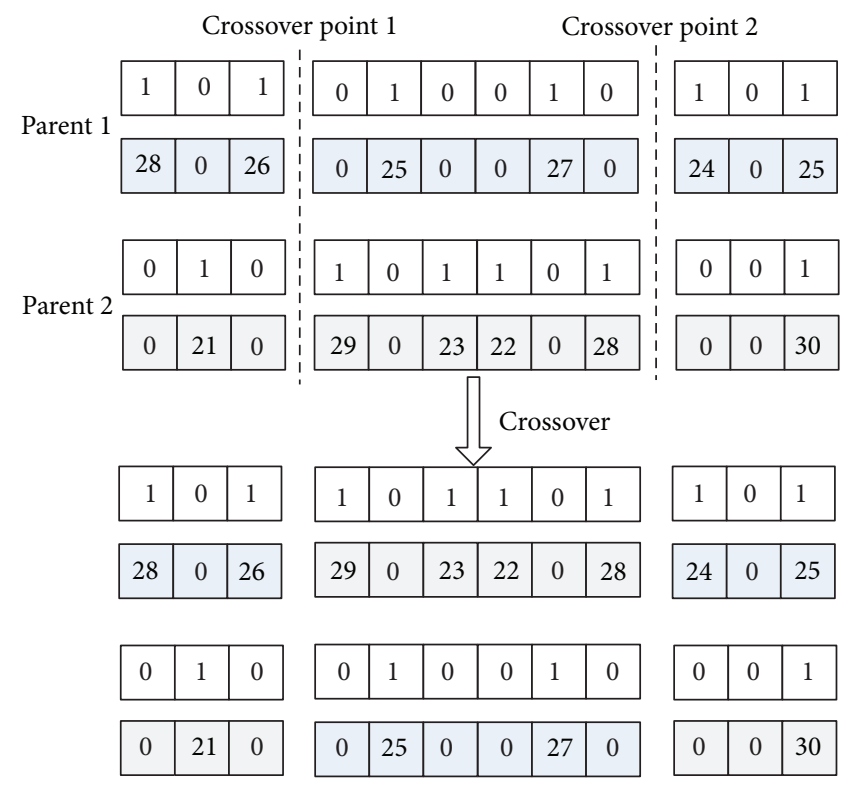

(b) Two-point crossover

FIGURE 4: Illustration of crossover operation.

3.4. Selection Operator. Roulette selection method is adopted in this paper. In each round, a uniform random number between zero and one is generated as the selection finger to determine the candidate individuals. The best individual preservation strategy is also applied to ensure the present best individual not being destroyed by genetic operation.

3.5. Crossover Operator. In view of the bi-layer coding mode, a synchronous crossover approach of the upper layer gene string and the lower layer gene string is adopted to guarantee the feasibility of offsprings. Meanwhile, single-point and twopoint crossover methods are comprehensively applied. The procedure of the crossover operation is as follows.

Step 1. Set the crossover probability $P_{c}$ and generate a random number $\lambda$ of uniform distribution within $[0,1]$ to be the judgment criterion.
Step 2. Do crossover operation if $\lambda \leq P_{c}$, where if $\lambda \leq P_{c} / 2$; then select a crossover point randomly and exchange the gene strings associated with both the upper layer and the lower layer beside the crossover point of parental chromosomes to get two offspring chromosomes. If $\left(P_{c} / 2\right)<\lambda \leq P_{c}$, two crossover points are selected randomly, and the gene strings between the two crossover points of parental chromosomes are exchanged to obtain offspring chromosomes.

Figure 4 gives an illustration of single-point crossover operation and two-point crossover operation.

3.6. Mutation Operator. Due to the fact that the number of marshalling cars is influenced by the choice of the path, which means that the values of the lower layer gene string are influenced by the values of the upper layer gene string, the following algorithm is designed. 


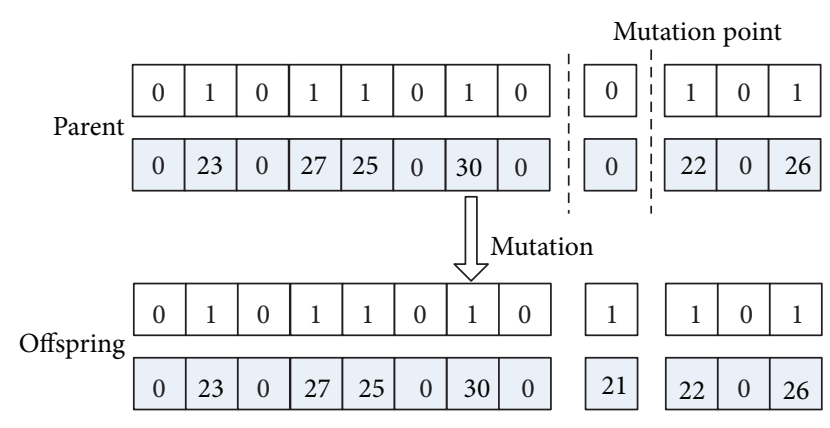

FIGURE 5: Illustration of mutation operation.

Step 1. Mutation probability $P_{m}$ is set, and a random number $\lambda^{\prime}$ of uniform distribution at $[0,1]$ is generated to be the judgment criterion.

Step 2. One mutation point is selected randomly to be the mutation position of the upper layer gene and the lower layer gene.

Step 3. Do mutation operation if $\lambda^{\prime} \leq P_{m}$. Firstly, mutation is operated on the upper layer chromosome, and then the value of the lower layer gene is adjusted according to the upper layer. If the value of the upper layer gene changes from 1 to 0 , then the value of the corresponding lower layer gene turns from a positive integer to 0 . Inversely, if the value of the upper layer gene changes from 0 to 1 , then the value of the corresponding lower layer gene turns from zero to a positive integer.

The illustration of the mutation operation is shown in Figure 5.

\section{Numerical Example}

The railway physical network shown as Figure 6 is structured to verify the proposed model and the algorithm. In this figure, the circles indicate the railway stations that deal with the services of express freight trains, while the edges indicate the sections. Relative parameter values are shown in Tables 1 and 2. The information of express freight demand $O D$, demand volume, desired minimum service frequency, and maximum transit time of shippers, as well as candidate paths of each demand is included in Table 1. In Table 2, the connected stations of each section, running time, carrying capacity, and maximum and minimum number of marshalling cars in each section are given. With regard to the running time in each section, the operation time in the connected stations is taken into account and that of the two directions is consistent. As for the carrying capacity of each section, it just means the allowed capacity taken up by express freight trains. Supposing the time of original departure and final arrival is 4 hours, the transit time of each demand can be obtained by summing up the running time on all the sections in the candidate path, the original departure, and the final arrival time.

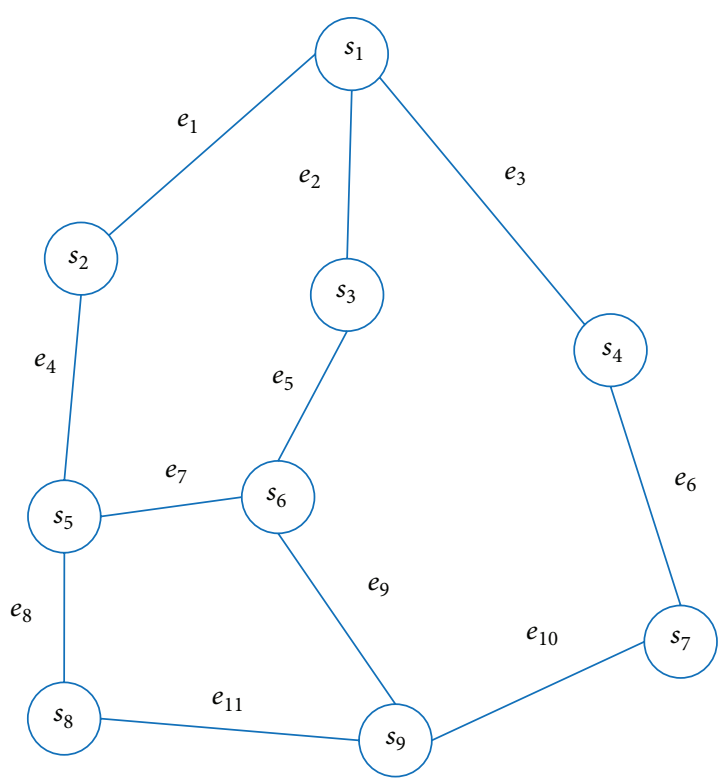

FIGURE 6: Structure of railway physical network.

TABLE 1: Freight demands and their candidate paths.

\begin{tabular}{lcccc}
\hline $\begin{array}{l}\text { Demand } \\
\text { OD }\end{array}$ & $\begin{array}{c}\text { Demand } \\
\text { volume }\end{array}$ & $\begin{array}{c}\text { Desired service } \\
\text { frequency }\end{array}$ & $\begin{array}{c}\text { Desired } \\
\text { transit time }\end{array}$ & $\begin{array}{c}\text { Candidate } \\
\text { paths }\end{array}$ \\
\hline$s_{1}-s_{5}$ & 25 & 1 & 15 & $\begin{array}{c}s_{1}-s_{2}-s_{5} \\
s_{1}-s_{3}-s_{6}-s_{5}\end{array}$ \\
\hline$s_{1}-s_{6}$ & 60 & 1 & 13 & $\begin{array}{c}s_{1}-s_{3}-s_{6} \\
s_{1}-s_{2}-s_{5}-s_{6}\end{array}$ \\
\hline$s_{1}-s_{9}$ & 78 & 2 & 20 & $\begin{array}{c}s_{1}-s_{3}-s_{6}-s_{9} \\
s_{1}-s_{2}-s_{5}-s_{8}-s_{9} \\
s_{1}-s_{4}-s_{7}-s_{9}\end{array}$ \\
\hline$s_{2}-s_{8}$ & 50 & 2 & 18 & \begin{tabular}{c}
$s_{2}-s_{5}-s_{8}$ \\
\hline$s_{3}-s_{5}$
\end{tabular} \\
\hline & 24 & 1 & 12 & $\begin{array}{c}s_{3}-s_{6}-s_{5} \\
s_{3}-s_{1}-s_{2}-s_{5}\end{array}$ \\
\hline$s_{4}-s_{9}$ & 26 & 1 & 15 & $\begin{array}{c}s_{4}-s_{7}-s_{9} \\
s_{4}-s_{1}-s_{3}-s_{6}-s_{9}\end{array}$ \\
\hline$s_{5}-s_{9}$ & 61 & 2 & 14 & $\begin{array}{c}s_{5}-s_{8}-s_{9} \\
s_{5}-s_{6}-s_{9}\end{array}$ \\
\hline$s_{6}-s_{7}$ & 46 & 1 & 16 & $\begin{array}{c}s_{6}-s_{9}-s_{7} \\
s_{6}-s_{3}-s_{1}-s_{4}-s_{7}\end{array}$ \\
\hline
\end{tabular}

Furthermore, the maximum departure and arrival capacity of all the stations are 5 trains.

The proposed method is applied to solve the numerical example. The size of the population is 30 and the number of total iteration is 200 . The crossover probability is 0.95 and the mutation probability is 0.15 . After iterating 116 generations, the satisfactory solution was obtained. The objective function value is 363 , which means that 363 cars of freight are transported and the satisfied degree of shippers' transport volume demand is up to 99.73 percent. For clarity, Table 3 is adopted to denote the operation plan of express freight trains, including origin and destination stations, running 
TABLE 2: Running time, carrying capacity, and requirement number of train marshalling cars of each section.

\begin{tabular}{lcccc}
\hline Section & $\begin{array}{c}\text { Connected } \\
\text { stations }\end{array}$ & $\begin{array}{c}\text { Running } \\
\text { time }\end{array}$ & $\begin{array}{c}\text { Carrying } \\
\text { capacity }\end{array}$ & $\begin{array}{c}\text { Maximum and } \\
\text { minimum number of } \\
\text { marshalling cars }\end{array}$ \\
\hline$e_{1}$ & $s_{1}, s_{2}$ & 6 & 5 & $35 / 25$ \\
$e_{2}$ & $s_{1}, s_{3}$ & 4 & 5 & $35 / 25$ \\
$e_{3}$ & $s_{1}, s_{4}$ & 7 & 5 & $35 / 25$ \\
$e_{4}$ & $s_{2}, s_{5}$ & 4 & 5 & $35 / 25$ \\
$e_{5}$ & $s_{3}, s_{6}$ & 3 & 5 & $30 / 20$ \\
$e_{6}$ & $s_{4}, s_{7}$ & 4 & 5 & $30 / 20$ \\
$e_{7}$ & $s_{5}, s_{6}$ & 2 & 5 & $30 / 20$ \\
$e_{8}$ & $s_{5}, s_{8}$ & 3 & 5 & $30 / 20$ \\
$e_{9}$ & $s_{6}, s_{9}$ & 4 & 5 & $30 / 20$ \\
$e_{10}$ & $s_{7}, s_{9}$ & 5 & 5 & $30 / 20$ \\
$e_{11}$ & $s_{8}, s_{9}$ & 4 & 5 & $30 / 20$ \\
\hline
\end{tabular}

TABLE 3: Operation plan of express freight trains.

\begin{tabular}{lccc}
\hline $\begin{array}{l}\text { Origin and } \\
\text { destination stations of } \\
\text { trains }\end{array}$ & $\begin{array}{c}\text { Running } \\
\text { path }\end{array}$ & $\begin{array}{c}\text { Number of } \\
\text { marshalling } \\
\text { cars }\end{array}$ & $\begin{array}{c}\text { Service } \\
\text { frequency }\end{array}$ \\
\hline$s_{1}-s_{5}$ & $s_{1}-s_{2}-s_{5}$ & 25 & 1 \\
$s_{1}-s_{6}$ & $s_{1}-s_{3}-s_{6}$ & 30 & 2 \\
$s_{1}-s_{9}$ & $s_{1}-s_{3}-s_{6}-s_{9}$ & 26 & 3 \\
$s_{2}-s_{8}$ & $s_{2}-s_{5}-s_{8}$ & 25 & 2 \\
$s_{3}-s_{5}$ & $s_{3}-s_{6}-s_{5}$ & 24 & 1 \\
$s_{4}-s_{9}$ & $s_{4}-s_{7}-s_{9}$ & 26 & 1 \\
$s_{5}-s_{9}$ & $s_{5}-s_{8}-s_{9}$ & 30 & 2 \\
$s_{6}-s_{7}$ & $s_{6}-s_{9}-s_{7}$ & 23 & 2 \\
\hline
\end{tabular}

path, number of marshalling cars, and the service frequency of each train.

The test result shows that there are 8 origin and destination pairs to run express trains, the service frequency of which are from 1 to 3 , and fourteen express freight trains are operated to transport the demands. The number of marshalling cars for these trains is between 23 and 30. Although some car flows do not choose the shortest path according to the running time, shipper demands on service frequency and transit time are ensured; meanwhile, all capacity constraints are also met.

\section{Conclusion}

Organizing railway express freight transportation according to shipper demands has great significance for improving the market competence of railway freight transportation, as well as promoting the rational division of transportation modes. This paper proposed an optimization method for the operation plan of express freight trains based on shipper demands. An integer programming model considering shipper demands on transport volume, service frequency, and transit time was established under flexible marshalling condition. A heuristic genetic algorithm with bi-layer coding method that can respond to the characteristics of the model and suit the problem of large scale network was designed. Finally, a numerical example was applied to verify the effectiveness of the model and the algorithm. The result showed that the proposed method can solve the operation plan of single group express freight trains, while the solving time can satisfy the requirement of railway operation. As a matter of fact, multigroup express freight trains are also in operation; thus, the operation problems of these trains will also be studied. Moreover, operation optimization of express freight trains for different kinds of goods and several grades of trains will also be considered to expand the scope of application.

\section{Conflict of Interests}

The authors declare that there is no conflict of interests regarding the publication of this paper.

\section{Acknowledgments}

This work was supported by National Natural Science Foundation Project of China under Grant nos. 61263027 and 61104175 and Young Scholars Science Foundation of Lanzhou Jiaotong University under Grant no. 2012031.

\section{References}

[1] E. Savesberg, Innovation in European Freight Transportation: Basics, Methodology and Case Studies for European Markets, Springer, Berlin, Germany, 2008.

[2] J. A. Pazour, R. D. Meller, and L. M. Pohl, "A model to design a national high-speed rail network for freight distribution," Transportation Research A, vol. 44, no. 3, pp. 119-135, 2010.

[3] B. L. Lin, S. N. Zhu, and S. W. He, "The optimal model of the direct train formation plan for loading area," China Railway Science, vol. 16, no. 2, pp. 117-120, 1995.

[4] T. Crainic, J. Ferland, and J. Rousseau, "A tactical planning model for rail freight transportation," Transportation Science, vol. 18, no. 2, pp. 165-184, 1984.

[5] A. Marín and J. Salmerón, "Tactical design of rail freight networks, part I: exact and heuristic methods," European Journal of Operational Research, vol. 90, no. 1, pp. 26-44, 1996.

[6] M. Yaghini, M. Seyedabadi, and M. M. Khoshraftar, "A population-based algorithm for the railroad blocking problem," Journal of Industrial Engineering International, vol. 8, pp. 1-11, 2012.

[7] D. R. Martinelli and H. Teng, "Optimization of railway operations using neural networks," Transportation Research C, vol. 4, no. 1, pp. 33-49, 1996.

[8] T. G. Crainic, "Service network design in freight transportation," European Journal of Operational Research, vol. 122, no. 2, pp. 272-288, 2000.

[9] C. Lin and S. Chen, "The hierarchical network design problem for time-definite express common carriers," Transportation Research B, vol. 38, no. 3, pp. 271-283, 2004.

[10] A. Ceselli, M. Gatto, M. E. Lübbecke, M. Nunkesser, and H. Schilling, "Optimizing the Cargo Express service of Swiss Federal Railways," Transportation Science, vol. 42, no. 4, pp. 450-465, 2008. 
[11] A. Ben-Tal, A. Nemirovski, and M. F. Gorman, "Santa Fe railway uses an operating-plan model to improve its service design," Interfaces, vol. 28, no. 4, pp. 1-12, 1998.

[12] Y. Wang and J. Liu, "Research on the optimization method of railway parcel express trains plan," Jounal of Transportation System Engineering Information Technology, vol. 7, no. 3, pp. 125129, 2007.

[13] C. A. Yano and A. M. Newman, "Scheduling trains and containers with due dates and dynamic arrivals," Transportation Science, vol. 35, no. 2, pp. 181-191, 2001.

[14] B. Crevier, J. Cordeau, and G. Savard, "Integrated operations planning and revenue management for rail freight transportation," Transportation Research B, vol. 46, no. 1, pp. 100-119, 2012.

[15] Y. Guo, S. He, and B. Wang, "Research on optimization of scheduled transit train operating plan," Journal of the China Railway Society, vol. 33, no. 5, pp. 8-13, 2011.

[16] M. Gen and R. Cheng, Genetic Algorithms and Engineering Optimization, John Wiley \& Sons, New York, NY, USA, 2000.

[17] H. M. Niu and X. S. Zhou, "Optimizing urban rail timetable under time-dependent demand and oversaturated conditions," Transportation Research C, vol. 36, pp. 212-230, 2013.

[18] H. M. Niu and M. H. Zhang, "An optimization to schedule train operations with phase-regular framework for intercity rail lines," Discrete Dynamics in Nature and Society, vol. 2012, Article ID 549374, 13 pages, 2012. 


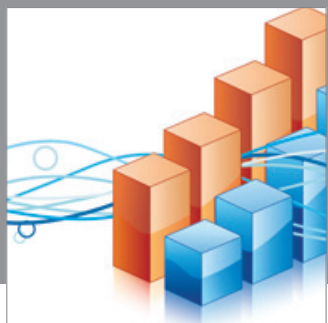

Advances in

Operations Research

mansans

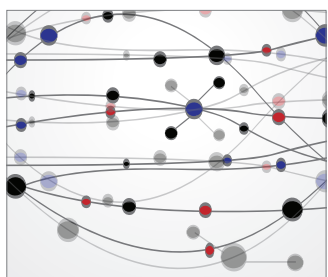

The Scientific World Journal

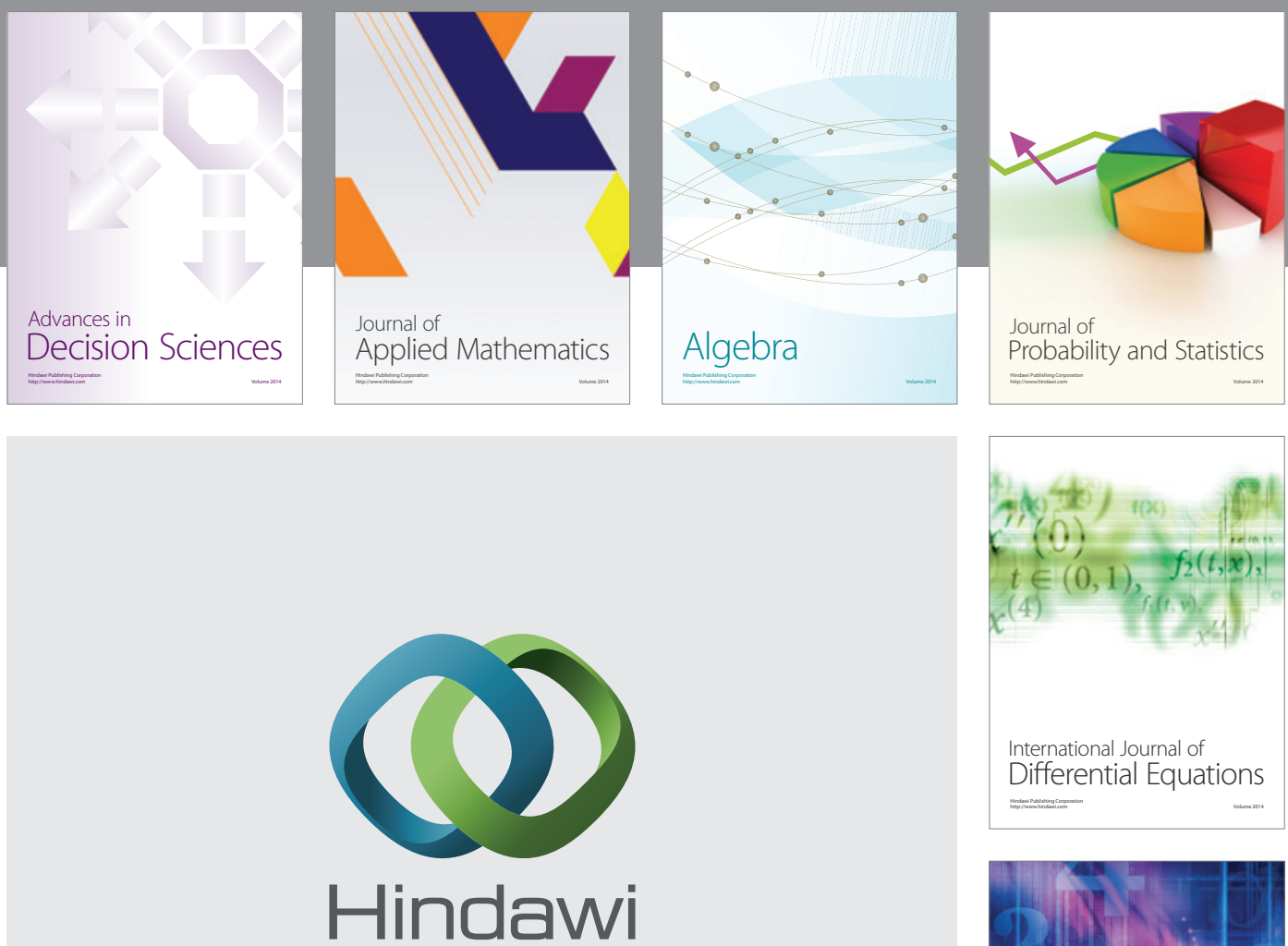

Submit your manuscripts at http://www.hindawi.com
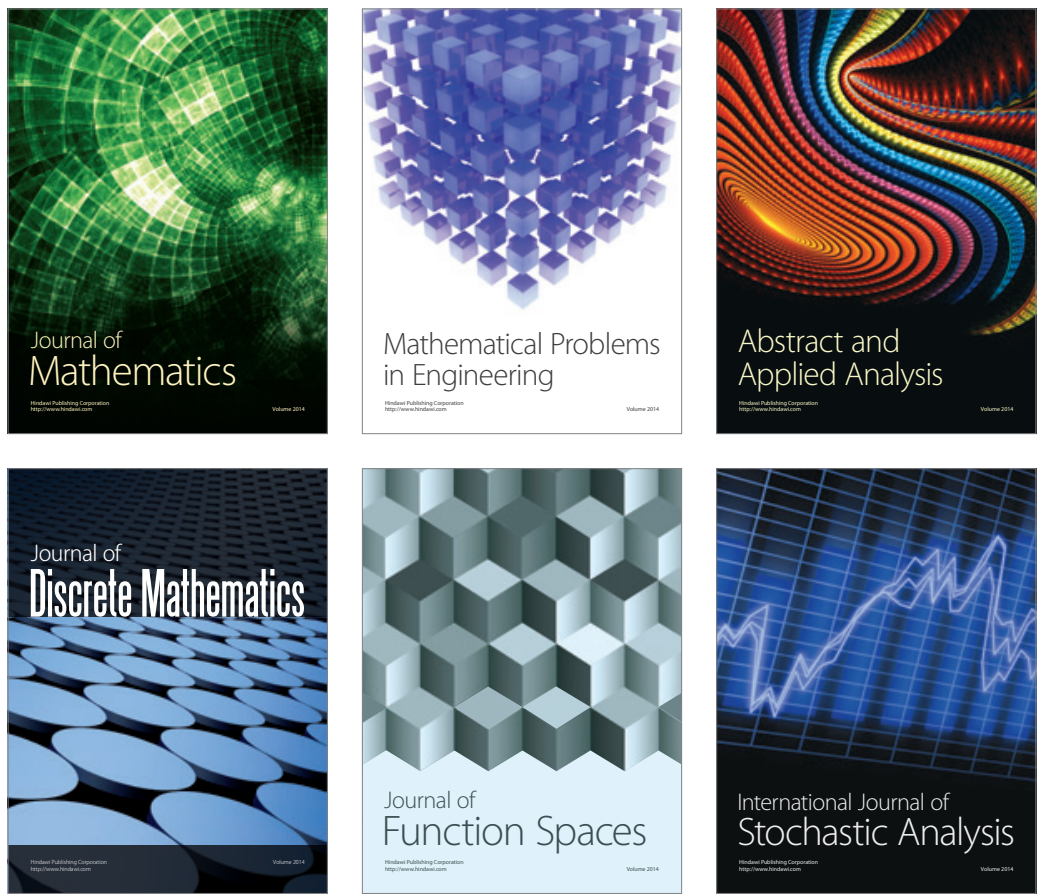

Journal of

Function Spaces

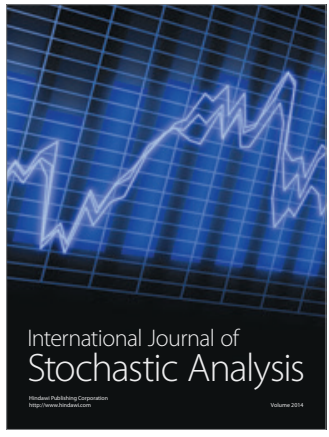

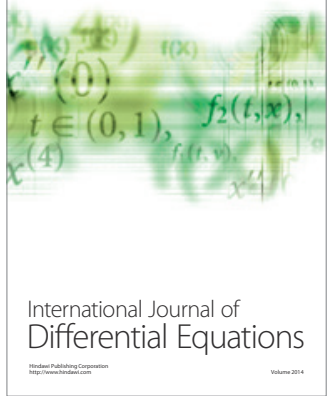
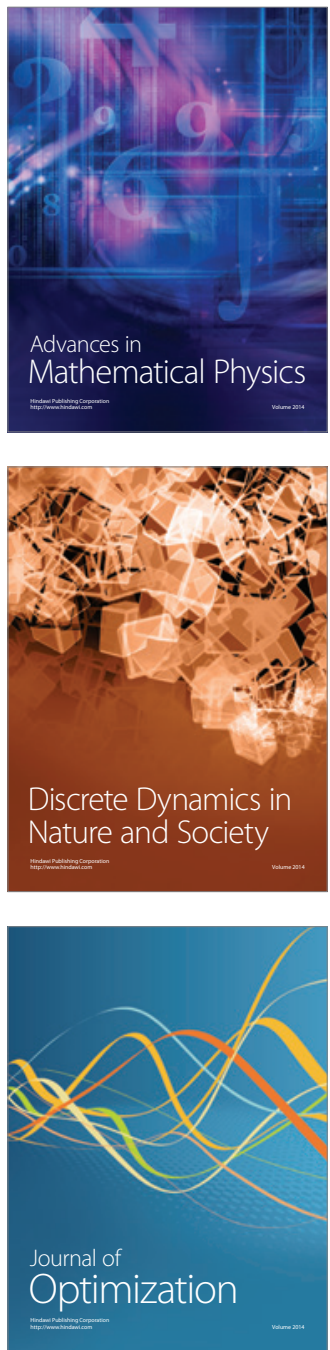